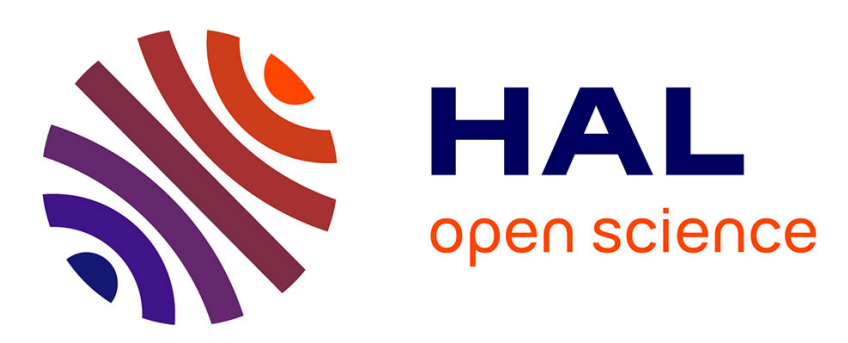

\title{
The effects of cutting intensity and neighbour species on plants of Lolium perenne, Poa annua, Poa trivialis and Trifolium repens
}

George Titus Barthram, Geoffrey Richard Bolton, David Andrew Elston

\section{- To cite this version:}

George Titus Barthram, Geoffrey Richard Bolton, David Andrew Elston. The effects of cutting intensity and neighbour species on plants of Lolium perenne, Poa annua, Poa trivialis and Trifolium repens. Agronomie, 1999, 19 (6), pp.445-456. hal-00885943

\section{HAL Id: hal-00885943 \\ https://hal.science/hal-00885943}

Submitted on 1 Jan 1999

HAL is a multi-disciplinary open access archive for the deposit and dissemination of scientific research documents, whether they are published or not. The documents may come from teaching and research institutions in France or abroad, or from public or private research centers.
L'archive ouverte pluridisciplinaire HAL, est destinée au dépôt et à la diffusion de documents scientifiques de niveau recherche, publiés ou non, émanant des établissements d'enseignement et de recherche français ou étrangers, des laboratoires publics ou privés. 


\title{
The effects of cutting intensity and neighbour species on plants of Lolium perenne, Poa annua, Poa trivialis and Trifolium repens
}

\author{
*George Titus Barthramª, Geoffrey Richard Bolton ${ }^{\mathrm{a}}$, David Andrew Elston ${ }^{\mathrm{b}}$ \\ ${ }^{a}$ Macaulay Land Use Research Institute, Hartwood Research Station, Shotts, ML7 4JY, UK \\ ${ }^{\mathrm{h}}$ Biomathematics and Statistics Scotland, MLURI, Craigiebuckler, Aberdeen, AB15 8QH, UK
}

(Received 6 October 1998; accepted 20 May 1999)

\begin{abstract}
The species composition of grass swards can be altered by differences in defoliation intensity. Differences in the response of plants of different species to defoliation intensity could be responsible, in part, for such differences in species composition. Our objective was to characterise the effects of defoliation intensity, in interaction with neighbour species, on the numbers of tillers per plant and plant mass of Lolium perenne, Trifolium repens, Poa annua and Poa trivialis. We compared the effects of high and low intensities of defoliation on single target plants grown in $1 \mathrm{~m}^{2}$ plots of neighbour species. There were all possible combinations of target species and monocultures of neighbour species, with the same list of species used as targets and neighbours. Relative to L. perenne, $P$. annua had more tillers per plant and greater mass under the high than the low intensity cutting treatment. Thus, the effects of defoliation on plants can partly explain differences in the proportion of $P$. annua in short and tall swards dominated by $L$. perenne. There was no evidence that this was also true for $P$. trivialis. However, the results did predict that a low herbage height or biomass around mid-May might lead to a reduction in the proportion of $P$. trivialis in a pasture. As a neighbour, $L$. perenne reduced the number of tillers, or growing points, on target plants. $T$. repens as a neighbour increased the height of the target plants and it increased the plant mass of $P$. trivialis (perhaps as a result of a temporal niche separation). The Poa species as neighbours only affected the heights of the target plants. Neighbour species did not significantly affect the mass per tiller of the target plants. (C Inra/Elsevier, Paris.)
\end{abstract}

\section{Lolium perenne / Trifolium repens / Poa annua / Poa trivialis / defoliation}

Résumé - Effets de la fréquence des coupes et des espèces voisines sur les plants de Lolium perenne, Poa annua, Poa trivialis et Trifolium repens. La composition botanique des surfaces herbeuses peut être altérée par une différence d'intensité de défoliation. Les différences de réponse à l'intensité de défoliation de différentes espèces herbacées pourraient être, en partie, responsables des variations dans les compositions botaniques observées. Notre objectif était de

Communicated by Gérard Guyot (Avignon, France)

* Correspondence and reprints

t.barthram@mluri.sari.ac.uk 
caractériser les effets de l'intensité de défoliation et l'influence de la nature des espèces voisines, sur le nombre de talles par plante et la biomasse de Lolium perenne, Trifolium repens, Poa annua and Poa trivialis. Nous avons comparé les effets d'une défoliation de faible ou de forte intensité sur une plante unique (espèce cible) cultivée au sein de plantes d'une autre espèce (espèce voisine), sur une parcelle d'un mètre carré. Le dispositif expérimental incluait toutes les combinaisons possibles entre espèce cible et espèce voisine. Comparée à $L$. perenne, $P$. annua avait plus de talles par plante et une plus grande biomasse lorsqu'elle était soumise à un régime de forte défoliation plutôt que de faible défoliation. Donc les effets de la défoliation peuvent partiellement expliquer les différentes proportions de $P$. annua poussant dans des monocultures basses ou hautes de $L$. perenne. Ceci n'a pas été démontré pour $P$. trivialis. Cependant les résultats permettent de penser que le maintien sur prairie, à la mi-mai, d'une faible quantité d'herbage (biomasse ou hauteur des plantes) entraînerait une réduction dans la proportion de $P$. trivialis. En tant qu'espèce voisine, L. perenne induit une réduction du nombre de talles par plante de l'espèce cible. T. repens, en tant qu'espèce voisine, induit une augmentation de la hauteur de plante de l'espèce cible, et induit une augmentation de la biomasse chez $P$. trivialis (en conséquence peut-être d'une séparation temporelle de niche). Poa en tant qu'espèce voisine induit seulement une différence de taille sur l'espèce voisine. La nature de l'espèce voisine n'a pas eu d'effet significatif sur la masse par talle des espèces cibles. (C Inra/Elsevier, Paris.)

\section{Lolium perenne / Trifolium repens / Poa annua / Poa trivialis / défoliation}

\section{Introduction}

Manipulating the pattern of defoliation within a growing season can create differences in the species composition of swards. This has been demonstrated for a range of grassland species [13, 14, 20]. More recently it has been shown that the timing of conservation cuts (for silage or hay) can affect the proportion of Trifolium repens $\mathrm{L}$. in otherwise grazed Lolium perenne L.-T. repens swards [2, 3]. Consistent differences in defoliation intensity can also alter species composition. For example the ingress of Poa annua L. into L. perenne swards has been found to be greater with frequent than infrequent cutting [24]. Such compositional changes may be the result of the different effects of defoliation on the growth (including tillering) and death of plants of the different species.

In extensively managed $L$. perenne-T. repens pastures little or no fertiliser is applied and there is a consequent reduction in defoliation intensity which is associated with the invasion of unsown species [17]. The amounts of these unsown species can depend on mean sward surface height. For example Marriott (pers. comm.) found more $P$. annua (25\% of total sward as measured by inclined point quadrats) than $P$. trivialis $(1 \%)$ in a $4 \mathrm{~cm}$ sward originally sown with $L$. perenne and
$T$. repens, than in an $8 \mathrm{~cm}$ treatment where there was less $P$. annua ( $2 \%$ ) than P. trivialis (11\%). One way that such results could arise is through differential effects of defoliation on the numbers of tillers per plant and/or the mass of existing plants.

To gain more understanding of how defoliation affects the number of tillers per plant and plant mass in such swards we measured the effects of defoliation on plants of $L$. perenne, $T$. repens, $P$. trivialis and $P$. annua. We measured tillers per plant and plant mass, and calculated the related variable mean tiller mass. $L$. perenne and $T$. repens are widely sown and both Poa species are common in pastures in Britain [11], and throughout Europe [19].

Plants of these species grow in pastures with each other as neighbours. The identity of neighbouring species can affect the growth of pasture species. Evidence of this comes from a number of studies. For example, the horizontal spread of pasture species is dependent on the identity of the neighbouring species [22]. The growth of young plants of $L$. perenne is affected by the species of its neighbour [18]. Similarly tillering by seedlings of $L$. perenne is reduced by the presence of $P$. trivialis [12]. The characteristics of populations of T. repens can diverge according to the identity of their grass neighbour [23]. Thus, when quantifying the effects of defoliation on target plants of the four species of 
interest we grew the target plants with different neighbours. The neighbours we used were $L$. perenne, $T$. repens, $P$. trivialis or $P$. annua.

The principal variables of interest were tillers per plant, plant mass and tiller mass of the target plants. However, overtopping, and thus shading by neighbours, is an important way in which the growth of plants can be affected [15]. So to help explain any differences between target plants created by the cutting treatments we measured both plant heights and the amount of material produced above the heights of defoliation.

\section{Materials and methods}

The study was carried out at the Macaulay Land Use Research Institute's Hartwood Research Station, Shotts, Scotland. The soil was a poorly draining non-calcareous gley $\left(\mathrm{pH} 5.3\right.$, with $1.9 \mathrm{mg} \mathrm{L}^{-1}$ of extractable phosphorous and $108 \mathrm{mg} \mathrm{L}^{-1}$ of extractable potassium) developed on a clay loam till derived from sedimentary Carboniferous rocks. During the 5 years before the study the site had not received any fertiliser and had occasionally been grazed by sheep.

In May 1994 the site was ploughed and sown with $L$. perenne (c.v. Magella), $T$, repens (c.v. Menna), $P$. trivialis (c.v. Dasus) and $P$. annua (un-named collection, John Chambers Wild Flower Seeds, Kettering, NN15 $5 \mathrm{AJ})$ to create $1 \mathrm{~m}$ square plots of each of these species. At the same time, seed was also sown in modules $(4 \times 4$ $\times 5 \mathrm{~cm}$ deep) to create single plants of each species. In August, after the swards had been sprayed with herbicide (2,4-DB with linuron and MCPA) to control broadleaved weeds and had been cut, one of the single plants was transplanted into the centre of each $1 \mathrm{~m}$ square plot. This created all combinations of target plant species in the centre of $1 \mathrm{~m}$ square plots of neighbour species. Each target plant was identified by being placed within a $35 \mathrm{~mm}$ diameter plastic ring held on the ground with fence staples. In late August the area sown with neighbour species immediately surrounding each target plant was hand weeded and extra seed was sown to fill gaps. The swards were cut during September and October according to the treatments that were to be imposed from March in the following treatment year.

The plots were arranged in nine blocks. Within each block the neighbour and target species were arranged in independently randomised Graeco Latin Squares [8]. There were two, interlaced, Graeco Latin Squares in each block, one for each cutting intensity treatment. The resulting block consisted of four columns of eight adjacent rows of plots with columns separated by $1 \mathrm{~m}$ wide paths. A sample arrangement is shown in figure 1. The plots were cut either weekly at a height of $4 \mathrm{~cm}$ (high intensity cutting treatment) or every 5 weeks at $8 \mathrm{~cm}$

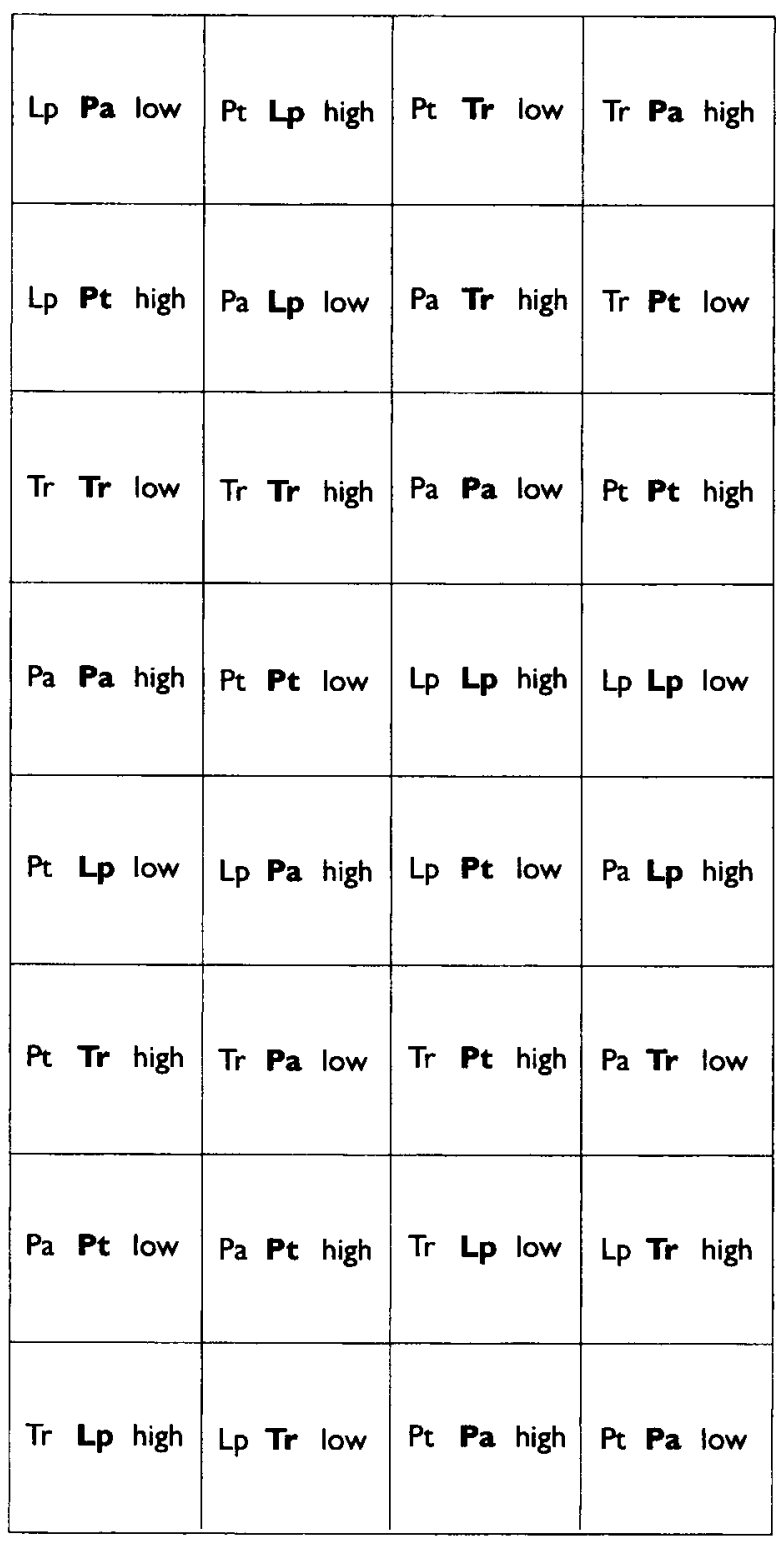

Figure 1. Treatment layout in an example block. Columns were separated by $1 \mathrm{~m}$ wide paths. The abbreviations in each cell indicate from left to right, the neighbour plant species, the target plant species and the cutting intensity. $\mathrm{Lp}=L$. perenne, $\mathrm{Tr}=T$. repens, $\mathrm{Pt}=P$. trivialis, $\mathrm{Pa}=P$. annua . 
(low intensity treatment) with a rotary mower which collected the cut material. The low intensity treatment cuts were made on 6 March, 10 April, 15 May, 19 June, 24 July, 28 August, 2 October and 6 November 1995. In this study, $10 \mathrm{~kg} \mathrm{~N} \mathrm{ha}^{-1}$ as a 22:11:11 ( $\left.\mathrm{N}_{2} \mathrm{P}_{2} \mathrm{O}_{5}: \mathrm{K}_{2} \mathrm{O}\right)$ fertiliser were applied to the whole site after each low intensity cut.

One block was randomly allocated to be used for leaf height measurements using the HFRO sward stick [1]. Weekly measurements, of the undisturbed heights of the tips of the three tallest laminae on each target plant, were made in this block immediately before all treatment cuts except the first.

Immediately after the first treatment cut, on 6 March, the above-ground parts of all the target plants from both the low and the high intensity cutting treatments in one randomly selected block were harvested and the block was then discarded. Data from this harvest describe the plants at the time that the experimental cutting treatments were imposed. Thereafter, immediately before each low intensity, 5 weekly treatment cut, the aboveground parts of all the target plants from both the low and the high intensity cutting treatments in one other randomly selected block were harvested and the block was then discarded. Care was taken to ensure that entire plants were harvested so that any break-up of plants of T. repens [5] did not bias the results. The harvested target plants were split into the portions above and below the cutting height. After counting the number of live tillers and $T$. repens growing points on each target plant the live material from both above and below the cutting height was dried overnight at $90^{\circ} \mathrm{C}$ and weighed. Data from these harvests describe the effects of the imposed treatments.

The plots became contaminated with self-sown weeds. This contamination was measured by centring a circular quadrat that was divided into eight equal sectors on the target plant and determining the species of the nearest neighbour to the target plant in each sector. These measurements were made immediately before each block was harvested, and in June and August in the block used for height determinations.

The height data have been analysed by Anova [10] in which the significance of treatment effects and their interactions with time were assessed by comparison with their respective error terms in a hierarchical analysis of variance. The three-way interaction at the plot level (that is between target plant species, neighbour species and cutting intensity) was used as an error term in the analysis of the plot-level treatment effects.

The data from the harvested target plants (that is, above-ground dry mass, number of live tillers or grow- ing points, dry mass per tiller and mass above the mowing height) have also been analysed by ANOVA. However, these data were analysed using a regression approach to cope with missing values in the data $(10 \%$ of the harvested plants died before being harvested, mainly near the end of the study). All the remaining variation was pooled to form a residual mean square against which other effects were tested for significance. The missing values permitted a robust analysis only up to the second order interactions. These data were skewed and so were transformed by taking natural logarithms (or logarithm of variate plus one to accommodate measurements of value zero) before analysis. Means averaged over time exclude the data collected at the first harvest (harvest 0 ) before initiation of the cutting treatments.

\section{Results}

\subsection{Tillers per plant}

The number of live tillers (or $T$. repens growing points) per target plant varied with the species of the target plant $\left(P<0.001, \mathrm{~F}_{3,109}=11.7\right)$ and the neighbour species $\left(P<0.001, \mathrm{~F}_{3,109}=15.9\right)$ (table I). There were also interactions between the target species and cutting intensity $(P<0.05$, $\left.\mathrm{F}_{3.109}=3.9\right)$ and the target species and harvest $\left(P<0.05, \mathrm{~F}_{18,109}=2.3\right)$ (figure 2$)$. The interaction between target species and neighbour species was marginally not significant $\left(P=0.55, \mathrm{~F}_{9.109}=1.9\right)$.

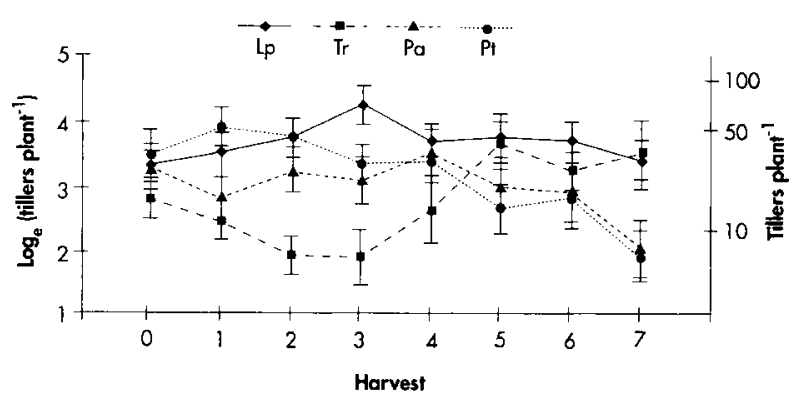

Figure 2. Mean numbers of live tillers on target plants of different species at each harvest. Values are the means for plants grown with $L$. perenne, $T$. repens, $P$. trivialis and $P$. amnua as neighbours. Harvest 0 was made at the time that the cutting treatments were started. Vertical bars indicate \pm standard error of transformed means. $\mathrm{Lp}=L$. perenne, $\mathrm{Tr}=T$. repens, $\mathrm{Pt}=P$. trivialis, $\mathrm{Pa}=P$. annua . 
Table I. The effects of neighbour species and cutting intensity on the numbers of tillers per plant of the target species. $\mathrm{Lp}=L$. perenne, $\mathrm{Tr}=T$. repens, $\mathrm{Pa}=P$. annua, $\mathrm{Pt}=P$. trivialis. Values are the means of seven harvests and show means \pm standard error of transformed $\left(\log _{\mathrm{e}}(\mathrm{count})\right)$ data, with the back-transformation of these means shown in brackets.

\begin{tabular}{lcccccccc}
\hline & \multicolumn{2}{c}{} & \multicolumn{5}{c}{ Tp } & \multicolumn{2}{c}{ Tr } & Parget species & Pa & Pt & Mean \\
\hline Neighbour & Lp & $2.33 \pm 0.27(10.3)$ & $2.20 \pm 0.32(9.0)$ & $2.14 \pm 0.33(8.5)$ & $2.64 \pm 0.28(14.1)$ & $2.34 \pm 0.15(10.3)$ \\
species & $\mathrm{Tr}$ & $4.16 \pm 0.26(64.1)$ & $2.21 \pm 0.29(9.1)$ & $3.21 \pm 0.32(24.7)$ & $4.01 \pm 0.29(55.3)$ & $3.45 \pm 0.14(31.6)$ \\
& $\mathrm{Pa}$ & $4.06 \pm 0.26(55.3)$ & $2.95 \pm 0.29(19.2)$ & $3.32 \pm 0.33(27.7)$ & $3.17 \pm 0.35(23.7)$ & $3.41 \pm 0.15(30.3)$ \\
& $\mathrm{Pt}$ & $4.30 \pm 0.27(74.1)$ & $2.81 \pm 0.33(16.7)$ & $2.98 \pm 0.29(19.7)$ & $3.15 \pm 0.26(23.3)$ & $3.37 \pm 0.14(29.0)$ \\
Cutting & high & $3.69 \pm 0.19(40.1)$ & $2.09 \pm 0.23(8.1)$ & $3.27 \pm 0.21(26.3)$ & $3.29 \pm 0.21(26.9)$ & \\
intensity & low & $3.74 \pm 0.19(42.1)$ & $3.00 \pm 0.21(20.0)$ & $2.54 \pm 0.23(12.7)$ & $3.19 \pm 0.20(24.4)$ & \\
& & & & & & & & \\
& mean & $3.72 \pm 0.13(41.1)$ & $2.54 \pm 0.16(12.7)$ & $2.91 \pm 0.15(18.3)$ & $3.24 \pm 0.15(25.1)$ & \\
\hline
\end{tabular}

Overall, the numbers of live tillers or growing points on the target plants were lowest when $L$. perenne was the neighbour (table I). Cutting intensity did not appear to affect the numbers of live tillers on plants of $L$. perenne or $P$. trivialis, but there were fewer growing points on plants of $T$. repens and more tillers on $P$. annua plants in the high than the low intensity treatment.

The patterns of change over time in the numbers of live tillers per plant varied with species (figure 2). The number of tillers on $L$. perenne plants was similar at the beginning and end of the study. In contrast the number of growing points on the $T$. repens plants increased between harvests 3 and 5 (during June, July and August) whilst tiller numbers on plants of the Poa species tended to decline during the season.

\subsection{Plant mass}

The amounts of live above-ground dry matter per plant (plant mass) varied with all main effects $\left(P<0.001, \mathrm{~F}_{3.109}=39.1\right.$ for target species, $\mathrm{F}_{3,109}=19.5$ for neighbour species, $\mathrm{F}_{1,109}=19.6$ for cutting intensity and $\mathrm{F}_{6,109}=33.5$ for harvest). There were also some small but significant interactions between target and neighbour species $\left(P<0.05, \mathrm{~F}_{9,109}=2.2\right)$, between target species and cutting intensity $\left(P<0.01, \mathrm{~F}_{3,109}=5.6\right)$ and between target species and harvest $(P<0.001$, $\mathrm{F}_{18,109}=4.8$ ). Plant mass tended to be lowest with $L$. perenne as a neighbour, but this effect was only significant $(P<0.05)$ for $L$. perenne target plants (table II). The mass of $P$. trivialis was greatest when T. repens was the neighbour. Plant masses were greater in the low than the high intensity cutting treatment, except for $P$. annua which was not significantly affected.

The masses of the target plants of all species were similar in spring and increased up to harvest 2 , 15 May (figure 3). The masses of the Poa species

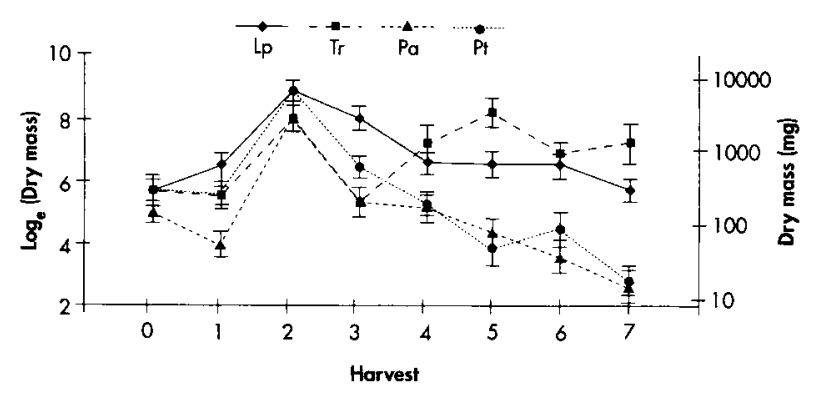

Figure 3. Dry live mass (mg) of target plants of different species at each harvest. Values are the means of target plant species grown with $L$. perenne, $T$. repens, $P$. trivialis and $P$. annua as neighbours. Harvest 0 was made at the time that the cutting treatments were started. Vertical bars indicate \pm standard error of transformed means. $\mathrm{Lp}=L$. perenne, $\operatorname{Tr}=T$. repens, $\mathrm{Pt}=P$. trivialis, $\mathrm{Pa}=P$. annua. 
Table II. The effects of neighbour species and cutting intensity on the masses (mg) of plants of the target species. $L P=L$. perenne, $\mathrm{Tr}=T$. repens, $\mathrm{Pa}=P$. annua, $\mathrm{Pt}=P$. trivialis. Values are the means of seven harvests and show means \pm standard error of transformed $\left(\log _{\mathrm{e}}(\mathrm{mg})\right)$ data, with the back-transformation of these means shown in brackets.

\begin{tabular}{llcccc}
\hline \multicolumn{7}{c}{} & & & \\
& & Tp & Tr & Pa & Pt \\
\hline Neighbour & Lp & $5.48 \pm 0.30(241)$ & $6.34 \pm 0.36(549)$ & $4.19 \pm 0.36(66)$ & $4.96 \pm 0.31(143)$ \\
species & $\mathrm{Tr}$ & $7.81 \pm 0.29(2458)$ & $6.63 \pm 0.33(756)$ & $4.95 \pm 0.36(140)$ & $6.48 \pm 0.32(650)$ \\
& $\mathrm{Pa}$ & $7.33 \pm 0.30(1531)$ & $7.25 \pm 0.33(1413)$ & $5.07 \pm 0.37(158)$ & $5.20 \pm 0.39(180)$ \\
& $\mathrm{Pt}$ & $7.48 \pm 0.30(1765)$ & $6.98 \pm 0.36(1075)$ & $5.03 \pm 0.32(153)$ & $5.60 \pm 0.29(268)$ \\
Cutting & high & $6.48 \pm 0.21(653)$ & $5.90 \pm 0.26(367)$ & $5.04 \pm 0.23(153)$ & $5.20 \pm 0.23(181)$ \\
intensity & low & $7.57 \pm 0.21(1947)$ & $7.68 \pm 0.24(2158)$ & $4.58 \pm 0.26(97)$ & $5.94 \pm 0.23(378)$ \\
& mean & $7.02 \pm 0.15(1124)$ & $6.79 \pm 0.18(886)$ & $4.81 \pm 0.17(122)$ & $5.56 \pm 0.16(261)$ \\
\hline
\end{tabular}

declined steadily thereafter with $L$. perenne declining more slowly.

\subsection{Tiller mass}

The dry mass of live material per tiller or growing point (tiller mass) varied with target species $\left(P<0.001, \mathrm{~F}_{3,108}=66.1\right)$. On the analysis scale, $\log _{\mathrm{e}}(\mathrm{mg})$, the means \pm standard error were, respectively, $3.31 \pm 0.12,4.25 \pm 0.14,1.90 \pm 0.14$, $2.32 \pm 0.13$ for $L$. perenne, $T$. repens, $P$. annua and $P$. trivialis. Back-transformation of these means produces values of $27.3,69.8,6.7$ and $10.2 \mathrm{mg}$, respectively. When averaged over all target and neighbour treatments tiller mass was also lower $\left(P<0.001, \mathrm{~F}_{1,108}=32.8\right)$ in the high intensity $(13.2 \mathrm{mg}$ ) than the low intensity $(28.7 \mathrm{mg})$ cutting treatment $(2.58 \pm 0.092$ versus $3.35 \pm 0.092$; $\left.\log _{e}(\mathrm{mg})\right)$. Neighbour species did not appear to affect the mass per tiller of any of the target plants $(P>0.2)$.

\subsection{Mass in the cut layer}

Each target plant was split into the portions above and below the mowing height, except at harvest 0 on 6 March. The dry mass of live material above the mowing height (that is, in the cut layer) varied significantly with target species $(P<0.001$,
$\left.\mathrm{F}_{3,109}=29.5\right)$, neighbour species $(P<0.01$, $\left.\mathrm{F}_{3,109}=4.0\right)$, cutting intensity $(P<0.01$, $\left.\mathrm{F}_{1,109}=8.8\right)$ and harvest $\left(P<0.001, \mathrm{~F}_{6,109}=16.0\right)$. There were also small but significant interactions between the target species and neighbour species $\left(P<0.05, \mathrm{~F}_{9,109}=2.4\right)$, target species and cutting intensity $\left(P<0.01, \mathrm{~F}_{3,109}=4.8\right)$, target species and harvest $\left(P<0.001, \mathrm{~F}_{18,109}=5.7\right)$, and between cutting intensity and harvest $\left(P<0.01, \mathrm{~F}_{6,109}=4.1\right)$.

All species except $P$. annua had a greater mass in the cut layer in the low intensity than the high intensity cutting treatment (table III). However, averaged over all species, this effect of cutting treatment was not apparent, until the third harvest on 15 May (figure 4a). The mass of material harvested in the cut layer from plants of $L$. perenne was lower when grown with conspecific neighbours than any other species (table III), but neighbour species had no effect on the average amount harvested from $T$. repens, $P$. trivialis or $P$. annua.

The seasonal pattern of production of material into the cut layer varied with target species (figure $4 b$ ). At the first harvest $L$. perenne had produced a greater mass than the other species and, together with $P$. trivialis, it produced the greatest amount at the second harvest (15 May). Then the masses of both species declined. This contrasts with the pattern seen in $T$. repens which produced little mass up to the third harvest (13 June) and then increased rapidly before declining in the autumn. 
Table III. The effects of neighbour species and cutting intensity on the mass of live material from target plants in the cut layer. $\mathrm{Lp}=L$. perenne, $\mathrm{Tr}=T$. repens, $\mathrm{Pa}=P$. annua, $\mathrm{Pt}=P$. trivialis. Values are the means of seven harvests and show means \pm standard error of transformed $\left(\log _{\mathrm{e}}(\mathrm{mg}+1)\right)$ data, with the back-transformation of these means shown in brackets.

\begin{tabular}{lccccc}
\hline & & \multicolumn{2}{c}{ Target species } & $\mathrm{Pa}$ & $\mathrm{Pt}$ \\
\hline Neighbour & $\mathrm{Lp}$ & $2.80 \pm 0.52(15.5)$ & $2.20 \pm 0.62(8.0)$ & $0.97 \pm 0.64(1.6)$ & $2.86 \pm 0.54(16.4)$ \\
species & $\mathrm{Tr}$ & $6.18 \pm 0.52(482.0)$ & $1.84 \pm 0.57(5.3)$ & $1.63 \pm 0.63(4.1)$ & $3.99 \pm 0.56(53.0)$ \\
& $\mathrm{Pa}$ & $5.34 \pm 0.52(206.7)$ & $2.11 \pm 0.57(7.3)$ & $0.58 \pm 0.65(0.8)$ & $2.27 \pm 0.62(8.7)$ \\
& $\mathrm{Pt}$ & $5.11 \pm 0.52(164.7)$ & $1.63 \pm 0.64(4.1)$ & $1.95 \pm 0.57(6.0)$ & $2.52 \pm 0.51(11.4)$ \\
Cutting & high & $4.09 \pm 0.37(58.9)$ & $1.01 \pm 0.46(1.7)$ & $1.87 \pm 0.41(5.5)$ & $2.28 \pm 0.40(8.8)$ \\
intensity & low & $5.63 \pm 0.37(278.8)$ & $2.89 \pm 0.41(17.1)$ & $0.71 \pm 0.46(1.0)$ & $3.56 \pm 0.40(34.1)$ \\
& & & & & \\
& mean & $4.86 \pm 0.26(127.4)$ & $1.94 \pm 0.31(6.0)$ & $1.30 \pm 0.30(2.7)$ & $2.91 \pm 0.28(17.4)$ \\
\hline
\end{tabular}
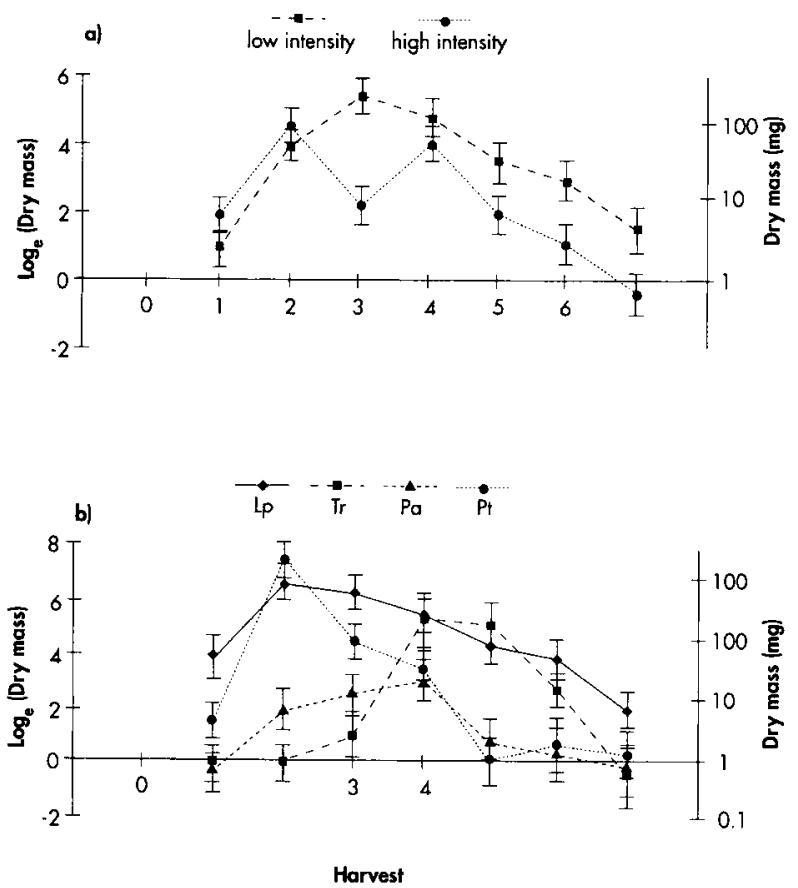

Figure 4. Dry mass of live material $(\mathrm{mg}$ ) in the cut layer from target plants at each harvest (no measurements were made at harvest 0 ): a) effects of cutting intensity, averages of four target and four neighbour species, and b) effects of different target species, averages of two cutting intensities and four neighbour species. Vertical bars indicate \pm standard error of transformed means. $\mathrm{Lp}=L$. perenne, $\mathrm{Tr}=T$. repens, $\mathrm{Pt}=P$. trivialis, $\mathrm{Pa}=P$. annua.

\subsection{Plant height}

Averaging over all measurements, the heights of the target species were different $(P<0.001$, $\left.\mathrm{F}_{3,7}=162.1\right)$ and interacted with cutting intensity $\left(P<0.001, \mathrm{~F}_{3,7}=42.9\right)$ and to a lesser extent with neighbour species $\left(P<0.05, \mathrm{~F}_{9.7}=5.9\right)$. L. perenne was the tallest, $P$. annua the shortest and the height of $P$. annua was similar under both cutting intensity treatments (table IV). L. perenne was tallest when grown with $T$. repens and shortest when grown with $P$. trivialis or $L$. perenne, $T$. repens was shortest when grown with the Poa species, $P$. annua was shortest when grown with $P$. annua, and $P$. trivialis was shortest when grown with $L$. perenne.

The seasonal variation in lamina height was examined by comparing the average heights within cutting periods, that is the times between each 5 weekly low intensity cut. There was an interaction between the heights of the target species, harvest and cutting intensity $\left(P<0.001, \mathrm{~F}_{17.35}=9.6\right)$. In the high intensity treatment (figure $5 a$ ) the peaks of maximum height were broader than in the low intensity treatment (figure $5 b$ ). In the low intensity cutting treatment the heights of both $L$. perenne and $P$. trivialis peaked during the third cutting period and thereafter the height of $P$. trivialis was much 
Table IV. The effects of the target species and cutting intensity on the heights $(\mathrm{cm})$ of target plants immediately before cutting. Values are the means of weekly measurements made between 6 March and 6 November.

\begin{tabular}{llccccc}
\hline Target species & & L. perenne & T. repens & P. annua & P. trivialis & s.e.d. \\
\hline Neighbour & L. perenne & 9.71 & 6.31 & 4.21 & 4.95 & \\
species & T. repens & 13.65 & 6.63 & 4.35 & 6.19 & \\
& P. annua & 10.97 & 4.57 & 2.59 & 5.27 & \multirow{2}{*}{0.62} \\
& P. trivialis & 9.19 & 4.86 & 4.11 & 7.05 & \\
Cutting & high & 7.02 & 3.54 & 3.76 & 4.07 & \\
intensity & low & 14.74 & 7.64 & 3.87 & 7.66 & 0.44 \\
Mean & & 10.88 & 5.59 & 3.81 & 5.86 & 0.31 \\
\hline
\end{tabular}

reduced. The peak height of $T$. repens was lower and later than that of the above two grasses and its timing was similar in the two cutting treatments. $P$. annua did not have a distinct peak.
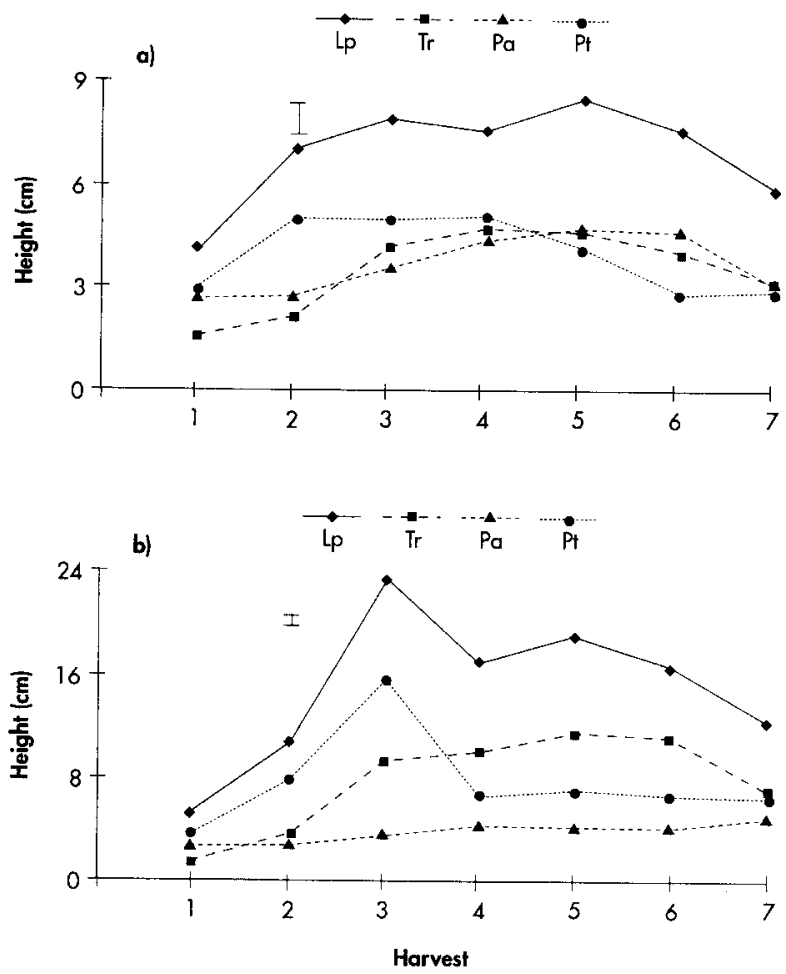

Figure 5. Effects of cutting intensity on the mean heights $(\mathrm{cm})$ of target plants (averaged over four neighbour species) in each cutting period between harvests: a) high intensity treatment, and b) low intensity cutting treatment. Vertical bar indicates s.e.d. $\mathrm{Lp}=$ L. perenne, $\mathrm{Tr}=T$. repens, $\mathrm{Pt}=P$. trivialis, $\mathrm{Pa}=P$. annua .
There was also evidence of an interaction between neighbour species and harvest $(P<0.05$, $\left.\mathrm{F}_{18,35}=2.1\right)$. Averaged across the target species, $T$. repens as a neighbour resulted in an increase (compared with the grasses) in the heights of the target plants during periods 4 and 5 which ended on 24 July and 28 August, respectively (figure 6).

\subsection{Neighbour species}

Self-sown weeds in this field study contaminated the intended neighbour species. Holcus lanatus L. was the most common weed, followed by Agrostis

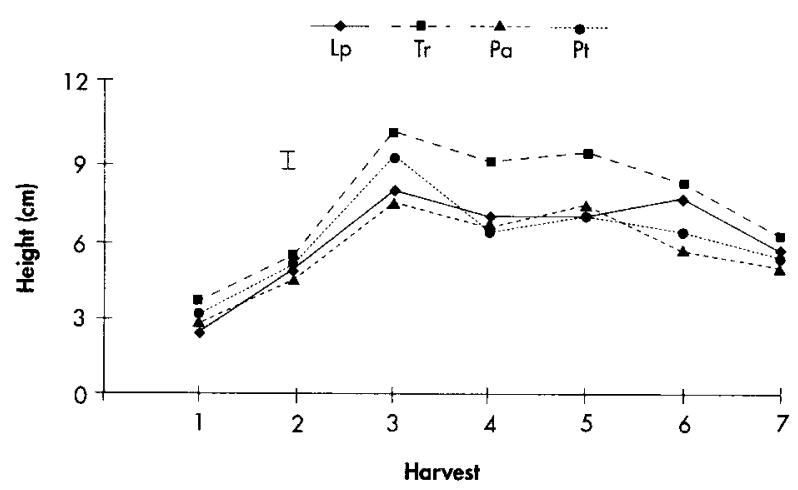

Figure 6. Effects of neighbour species (averaged over four target species) on the mean heights (cm) of target plants in the cutting period between each harvest. Vertical bar indicates s.e.d. $\mathrm{Lp}=L$. perenne, $\mathrm{Tr}=T$. repens, $\mathrm{Pt}=P$. trivialis, $\mathrm{Pa}=P$. annua . 
capillaris L., with Ranunculus repens L., Cerastium fontanum Baumg. and Bellis perennis L. also present. In the block used for height determination the overall proportions of neighbours which were the intended sown species were $0.77,0.25,0.49$ and 0.37 (s.e.d. 0.10) for $L$. perenne, $T$. repens, $P$. annua and $P$. trivialis neighbour species, respectively. Averaged over all measurements the equivalent values from the destructively harvested blocks were $0.60,0.35,0.50$ and 0.39 (s.e.d. 0.06). The main contaminating weed species were similar for all intended neighbour species $(P>0.30)$.

\section{Discussion}

\subsection{Experimental design}

The experimental design used just a single replicate of each treatment combination because of resource constraints, whilst the need for destructive harvesting of the plots meant that contiguous sets of plots had to be harvested together. These constraints led to all plots harvested on any one date being grown in close proximity to one another, and so any trends in soil type would contribute to additional between-date variation or interactions between treatment and date. However, the clear presence of the expected seasonal trends in the data, coupled with the random allocation of harvesting to blocks, suggests this potential problem may not have been too great. The use of higher-order interactions as a surrogate for random error in non-replicated experiments (as used here for the height measurements) is well established [8] and leads to conservative estimation if any such interactions are non-negligible. However, the fact that our analyses produced significant results suggests that they were not too conservative.

\subsection{Effects of cutting intensity}

As expected, cutting intensity altered the mean size of the above-ground parts of the different species. Different levels of herbivory, as opposed to cutting as used in this study, have a similar effect
[16]. Plant size was commonly reduced by the high compared with the low intensity cutting treatment, but with one exception. $P$. annua had similar (low) plant mass (table II) and heights (table IV) under both cutting treatments, and in contrast to the other species had more tillers per plant (table I) and greater mass in the cut layer (table III) under the high than the low intensity treatment. The importance of height in neighbour interactions has been recognised for many years (Keddy [15] quoting Clements et al. (1929)) and will have been important here. This importance follows from the general correlation between competitive ability and height of a species $[6,7]$, and between above-ground biomass and competitive ability [15]. When grown with $L$. perenne in this study, $P$. annua was most successful when its height was not greatly less than that of its neighbour. For instance, under the low intensity cutting treatment $P$. annua plants were on average 0.26 of the height and had 0.05 of the mass and 0.31 of the number of tillers of $L$. perenne. While under the high intensity treatment the height relative to $L$. perenne was 0.53 , and the relative mass had increased to 0.23 and the relative numbers of tillers had increased to 0.66 of that of $L$. perenne. Thus, $P$. annua appears well adapted to conditions in short $L$. perenne swards, but it does not change its morphology in response to the shaded conditions in taller swards. This is likely to reduce the photosynthetic capacity of the plant and put it at a disadvantage in tall pastures. $P$. annua always grew slowly and remained low in the sward, effectively avoiding defoliation and displaying its grazing avoidance strategy [4], rather than following a strategy of rapid growth and maximum resource capture. The relative differences, in plant mass and numbers of tillers per plant, between $P$. annua and L. perenne as a result of different intensities of defoliation offer one explanation for the greater amounts of $P$. annua in short compared with tall swards dominated by $L$. perenne [24].

The effect of the cutting treatments on the height of $P$. trivialis was not associated with differences in its number of tillers per plant, plant mass or mass in the cut layer that were not at least equalled by $L$. perenne and $T$. repens. Thus, this study does not demonstrate that changes in plant size as a result of 
maintained differences in defoliation intensity alone can affect the proportion of $P$. trivialis in $L$. perenne-T. repens swards. However, it is possible that frequencies or levels of severity of defoliation outside the range imposed here may have such effects.

Jones $[13,14]$ recognised critical times of the year when either resting a sward from defoliation or grazing it severely could alter the species composition of a sward. The timing of these critical periods depended on the species present, but in general, reducing defoliation intensity at the time of most rapid growth of a species in a mixture, or at the start of its active growth in spring, can increase its proportion in the sward. Similarly increasing defoliation intensity at these times can reduce the proportion in the sward. The results of this study show critical times for manipulating grass/clover proportions that are in agreement with earlier studies [3]. They also show that the maximum rate of herbage production of $P$. trivialis occurred between harvests 2 and 3 . This means that if the proportion of $P$. trivialis in a sward is amenable to manipulation through controlled changes in herbage quantity (perhaps through changes in plant population density) one critical time will be around mid-May, but for a shorter period than $L$. perenne is susceptible. $P$. annua did not have such distinctive periods of herbage production as the other species and thus might be less susceptible to changes in herbage quantity at critical times of the year. In our study, although the cutting treatments altered plant size, the relative timing of the changes in size of the different species was not affected by the cutting intensity treatments. So the timing of the critical periods described by Jones $[13,14]$ is unlikely to be altered by differences in the average defoliation intensity of swards.

\subsection{Effects of neighbour species}

The presence of self-sown contaminating species around the target plants means that the results do not describe the effects of monocultures of neighbours. However, as the species of the contaminants did not vary with the sown neighbour species we attribute the observed effects of the neighbour treatments to the sown species. The most likely effect of the presence of the self-sown species will have been to reduce the magnitude of the effects of the intended neighbour species on the target plants.

Bullock [6] defines a better competitor as one that suppresses competing species more than it is suppressed. In this sense $L$. perenne was the most competitive of the species examined. It grew most rapidly after defoliation (was tallest on average) and was in a position to pre-emptively capture the light resource. It reduced the spread of the other species by reducing tiller or growing point numbers (table I). In contrast, when grown as a target plant, its number of tillers and plant mass were not reduced by the other species. Its consistently greater height may have played a role in reducing the numbers of tillers per plant when $L$. perenne was the neighbouring species (table I), mediated through a reduced red/far-red light ratio as a result of shading by leaves $[9,21]$. L. perenne as a neighbour did not result in a reduction of the heights of target plants of $T$. repens or $P$. annua although it did have this effect on $L$. perenne and $P$. trivialis. It also reduced the mass in the cut layer produced by target plants of $L$. perenne, but not the other species (table III). So it appears to have affected the vertical distribution of the target species in different ways. In contrast, neither $L$. perenne nor the other species had an effect on the resources allocated to tillers (tiller masses were not affected by neighbours), even though neighbours did affect plant mass.

Compared with the other neighbour species $T$. repens had a positive or neutral effect on the target plants. It increased the height of the target plants (table IV) particularly during the middle of the season (figure 6), and increased the plant mass of $P$. trivialis (table II). The other target species did not increase in the same way as $P$. trivialis when grown with $T$. repens, but the other species did not have the same rapid spring growth followed by such a steep decline (figures $4 b$ and 5). The decline in $P$. trivialis roughly coincided with the time when plants of $T$. repens increased in size. This could lead to temporal niche separation that benefited the $P$. trivialis in terms of plant mass early in the season. Such a temporal niche separation could also 
explain why $P$. trivialis is so readily invaded by T. repens [13].

The effects of the Poa species as neighbours were confined to complex effects on height, with the response depending on species combination (table $I V)$. The lack of an effect on any of the other measures of plant size suggests that in a pasture, the presence of these species of Poa will have little effect on the productivity or tiller (or growing point) population densities of $L$. perenne and $T$. repens. Unless they affect the plant population densities of $L$. perenne or $T$. repens.

\section{Conclusion}

Of the species $L$. perenne, $T$. repens, $P$. trivialis and $P$. annua, plants of $L$. perenne were the most competitive. Differences between the proportion of $P$. annua in short and tall pastures dominated by $L$. perenne can be explained in part by the different effects of defoliation on plants of $L$. perenne and $P$. annua. There was no evidence that this was also true for $P$. trivialis. However, the results did predict that maintaining a low herbage quantity in a pasture between mid-May and mid-June might lead to a reduction in the proportion of $P$. trivialis in a sward. The results also suggest that $P$. trivialis and T. repens occupy different temporal niches.

Acknowledgements: We thank Carol Marriott and John Milne for helpful advice during the preparation of this paper, and Gwen Grelet and Claire Souchet for the translation. The Scottish Office Agriculture, Environment and Fisheries Department funded this work.

\section{References}

[1] Barthram G.T., Experimental techniques: The HFRO sward stick, H.F.R.O. Biennial Report 1984-1985.

[2] Barthram G.T., Grant S.A., The effects of management and plant variety on the composition, vertical structure and stock-carrying capacity of Lolium perenne-
Trifolium repens pastures, Grass Forage Sci. 49 (1994) 360-368.

[3] Barthram G.T., Grant S.A., Interactions between variety and the timing of conservation cuts on species balance in Lolium perenne-Trifolium repens swards, Grass Forage Sci. 50 (1995) 98-105.

[4] Bircham J.S., Hodgson J., The influence of sward condition on rates of herbage growth and senescence in mixed swards under continuous stocking management, Grass Forage Sci. 38 (1983) 323-331.

[5] Brock J.L., Hay M.J.M., Thomas V.J., Sedcole J.R., Morphology of white clover (Trifolium repens L.) plants in pastures under intensive sheep grazing, J. Agric. Sci. Camb. 111 (1988) 273-283.

[6] Bullock J.M., Plant competition and population dynamics, in: Hodgson J., Illius A.W. (Eds.), The Ecology and Management of Grazing Systems, CAB International, 1996, pp. 69-100.

[7] Caldwell M.M., Plant architecture and resource competition, Ecol. Stud. 61 (1987) 164-179.

[8] Cochrane W.G., Cox G.M., Experimental Design, John Wiley and Sons, 1957.

[9] Deregibus V.A., Sanchez R.A., Casal J.J., Effects of light quality on tiller production in Lolium spp, Plant Physiol. 72 (1983) 900-902.

[10] Genstat 5 Committee, Genstat, Rothamstead Experimental Station, Harpenden, Hertfordshire AL5 2JQ, Harpenden, 1993.

[11] Grime J.P., Hodgson J.G., Hunt R., Comparative Plant Ecology, Hyman Ltd., London, 1988.

[12] Haggar R.J., Competition between Lolium perenne and Poa trivialis during establishment, Grass Forage Sci. 34 (1979) 27-36.

[13] Jones M.G., Grassland management and its influence on the sward. Pt I. Factors influencing the growth of pasture plants, Emp. J. Exp. Agric. 1 (1933) 43-57.

[14] Jones M.G., Grassland management and its influence on the sward. Pt II. The management of a clovery sward and its effects, Emp. J. Exp. Agric. 1 (1933) $122-128$

[15] Keddy P.A., Competitive heierarchies and centrifugal organisation in plant communities, in: Grace J.B., Tilman D. (Eds.), Perspectives on Plant Competition, Academic Press Inc., 1990, pp. 266-290.

[16] Louda S.M., Keeler K.H., Holt R.D., Herbivore influences on plant performance and competitive interactions, in: Grace J.B., Tilman D. (Eds.), Perspectives on Plant Competition, Academic Press Inc., 1990, pp. 414-444. 
[17] Marriott C.A., Bolton G.R., Common T.G., Small J.L., Barthram G.T., Effects of extensification of sheep grazing systems on animal production and species composition of the sward, in: Parente G., Frame J., Orsi S. (Eds.), Proceedings of the 16th general meeting of the European Grassland Federation Meeting, 1996, pp. 505-509

[18] Marriott C.A., Zuazua M.T., Tillering and partitioning of dry matter and nutrients in Lolium perenne growing with neighbours of different species: Effects of nutrient supply and defoliation, New Phytol. 132 (1996) 87-95.

[19] Rose F., Colour Identification Guide to the Grasses, Sedges, Rushes and Ferns of the British Isles and North-Western Europe, Viking, London, 1989.

[20] Sheath G.W., Boom R.C., Effects of NovemberApril grazing pressure on hill country pastures. 2.
Pasture species composition, N. Z. J. Exp. Agri. 13 (1985) 329-340.

[21] Smith H., Light quality, photoperception, and plant strategy, Annu. Rev. Plant Physiol. Plant Mol. Biol. 33 (1982) 481-518.

[22] Thorhallsdottir T.E., The dynamics of 5 grasses and white clover in a simulated mosaic sward, J. Ecol. 78 (1990) 909-923.

[23] Turkington R., The growth, distribution and neighbour relationships of Trifolium repens in a permanent pasture.5. The coevolution of competitors, J. Ecol. 77 (1989) 717-733.

[24] Wells G.J., Haggar R.J., The ingress of Poa annua into perennial ryegrass swards, Grass Forage Sci. 39 (1984) 297-303. 